\title{
ÍNDICES DE QUALIDADE DE VIDA NO BRASIL: INSTRUMENTO PARA ANÁLISE CRÍTICA DOS INDICADORES E DAS POLÍTICAS PÚBLICAS
}

\section{INDEX OF QUALITY OF LIFE IN BRAZIL: INSTRUMENT FOR CRITICAL ANALYSIS OF THE POINTERS AND THE PUBLIC POLITICS}

\author{
Marco Antonio Bettine de Almeida ${ }^{1}$; Gustavo Luis Gutierrez ${ }^{2}$ \\ ${ }^{1}$ Doutorando do programa de Pós-graduação da Faculdade de Educação Física da Unicamp - \\ marcobettine@yahoo.com.br \\ ${ }^{2}$ Professor Titular da Faculdade de Educação Física da Unicamp \\ gutierrez@fef.unicamp.br
}

\begin{abstract}
Resumo
Este estudo pretende analisar criticamente os índices de qualidade de vida divulgados pelo IBGE (Índice Brasileiro de Geografia Estatística) e IDH (índice de Desenvolvimento Humano), apontando que somente deverão ser analisados de uma forma abrangente, não de modo singular, não priorizando alguns indicadores em detrimento de outros. Fez-se um estudo exploratório, bibliográfico e analítico dialogando com autores da área e apontando os gargalos de políticas públicas nos índices em separado. Concluiu-se que os estudos de qualidade de vida deve mediar com muito cuidado os números que se apresentam porque muitas vezes se mostram fragilizados quando se pensa em políticas de qualidade de vida de grande ação social.
\end{abstract}

Palavras chave: Qualidade de vida, políticas públicas, ação social.

\section{Introdução}

Existe a esperança que as novas tecnologias irão conduzir para uma vida mais saudável, maiores liberdades sociais, conhecimento e meios de vida mais dignos. Esta posição, ao analisar os dados objetivos, é verdadeira, pois os avanços sociais do século XX apontam para a melhoria do desenvolvimento humano, tendo íntima relação com os avanços tecnológicos (Relatório do Desenvolvimento Humano - IDH, 2001, p.2). Podemos citar como exemplos que reforçam esta colocação a redução da subnutrição na Ásia do Sul em 30 anos de 40\% para 23\%; o acesso ao conhecimento livre pela Internet; a produção e distribuição de novos medicamentos e o maior rendimento agrícola nos países periféricos como o Brasil.

Cabe nos perguntar, porém, se estes dados objetivos e pontuais são de fatos indicadores confiáveis de uma melhora na qualidade de vida das pessoas (Gonçalves, 2004). O primeiro problema que se coloca nos estudos de Qualidade de Vida (QV) é distinguir quais são os avanços 
propostos com o intuito de melhoria da população daqueles que se referem às ações dispersas que acompanham a situação mundial, sem uma ação direta do poder público. O segundo ponto é a utilização de dados sem um rigor metodológico e sem as devidas análises. O terceiro ponto é a utilização dos dados para a política eleitoreira; onde um mesmo dado pode ser enfocado, como propaganda governista ou antigovernista, dependendo de como ele é apresentado. Neste estudo enfocaremos o primeiro ponto, porque a idéia deste trabalho é compreender os avanços tecnológicos, políticos, sociais e sua interferência na qualidade de vida das pessoas partindo de análises macro sociais. Não é a intenção entrar no mérito das metodologias dos dados, e muito menos entrar nos caminhos tortuosos da análise política.

A hipótese central deste trabalho é demonstrar a importância, para analisar o conjunto mais amplo de dados sobre a qualidade de vida, de distinguir os dados que fazem referência a manifestações especificas do próprio desenvolvimento do capitalismo ou de políticas econômicas, daqueles decorrentes de ações diretas do poder público através de políticas direcionadas à população. Neste sentido, o artigo vai expor e discutir alguns índices apresentados pelo IBGE (Instituto Brasileiro de Geografia Estatística) e pelo IDH, com o intuito de dar uma outra visão sobre os parâmetros que muitas vezes são utilizados para demonstrar avanços na qualidade de vida.

\section{Indicadores do IBGE e qualidade de vida}

\subsection{População Economicamente Ativa (IPEA)}

O primeiro indicador do IBGE (2005) que trata da qualidade de vida é o percentual da População Economicamente Ativa (PEA) por ramo de atividade. Um dos grandes avanços da humanidade, segundo Almeida (1998), é a diminuição da mão-de-obra empregada na agricultura em favor dos empregos no setor industrial e de serviços. $\mathrm{O}$ autor considera ser este um dos fatores mais importantes do aumento geral do padrão de vida. O decréscimo do percentual de mão-de-obra empregada na agricultura é utilizado como um indicador de desenvolvimento agrícola, pois menos empregados rurais é igual a mais máquinas, mais produção e maior produtividade, e também maior desenvolvimento econômico, segundo uma visão mais desenvolvimentista.

Este avanço deve ser ponderado por algumas questões, como: (a) a expulsão do pessoal do campo através de meios insidiosos, parte do processo de concentração de terras para viabilizar a agroindústria ou a valorização pura e simples - os grileiros; (b) a diminubição da economia rural familiar e o êxodo rural, dificultando a vida destas pessoas na cidade, aumentando o número de excluídos e desempregados - falta de crédito para o pequeno agricultor; (c) investimento em produtos da monocultura no mercado de commodity e redução dos produtos de primeira necessidade encarecendo-os, afetando principalmente o trabalhador de baixa-renda (cana de açúcar). 
Segundo o Relatório de Desenvolvimento Humano (2001) os índices do trabalho agrícola estão associados a condições de vida precárias se comparadas com a vida em cidades: maior incidência de doenças infecto-contagiosas, menor expectativa de vida, maior pobreza, pouco acesso a serviços etc. O deslocamento da PEA da agricultura para os serviços e a indústria segue trajetória idêntica ao deslocamento da população do campo para a cidade.

Segundo dados do IBGE (2005), em 1940, a mão-de-obra agrícola representava 66\% de toda a PEA, hoje responde por apenas 26\%. Esta mudança ocorreu com a incorporação da PEA pela indústria e pelo setor de serviços. A indústria, por seu turno, passou por um ponto de inflexão em 1980, a partir de então conhecemos a mudança de uma indústria que empregava uma fatia cada vez maior da PEA, para uma indústria que emprega cada vez menos. O avanço tecnológico provavelmente não permitirá a reversão de tal tendência. O trabalho na indústria está sendo substituído pelo mundo dos serviços. Talvez o maior desafio contemporâneo ao desenvolvimento brasileiro seja este conseguir alocar todo este contingente de trabalhadores que saem do campo, sem perspectivas e não encontram formas de acesso ao mercado de trabalho de maneira formal, entre outros motivos por falta de qualificação profissional.

Para uma qualidade de vida de maneira ampla e vista de maneira não-fragmentada, maior mecanização no campo, sem uma política pública de re-adequação de mão-de-obra, ou mesmo políticas de manutenção de famílias de economia familiar, proporciona gargalos em outros índices da qualidade de vida, como concentração de renda. Este é um ponto relevante de análise, os avanços seguem o desenvolvimento do capitalismo mundial, não é parte de uma política pública integrada entre os diversos setores, é possível inferir que os índices não refletem a melhoria na qualidade de vida como afirmou Almeida (1998), mas segue um padrão da lógica evolutiva do próprio sistema (MANTEGA, 1995).

\subsection{Taxa de Analfabetismo}

A taxa de analfabetismo é um indicador educacional. É consenso que ser ou não alfabetizado é fundamental para a qualidade de vida. A capacidade de ler e escrever dá acesso à informação, abre espaço em termos de oportunidade de emprego e possibilita uma integração social mais ampla. $\mathrm{O}$ analfabetismo diminuiu no Brasil do século XX em todas as suas grandes regiões.

Em 1940 a taxa de analfabetismo atingia a casa dos 61\%; no Plano Nacional de Desenvolvimento de 1995 era de 16\%. A diminuição ocorrida entre os censos de 1940 e 1980 é em si já bastante significativa: em 1980 o analfabetismo era de 35\%, uma redução de quase 50\% em quarenta anos. Vale notar ainda que a tendência de queda é ininterrupta e se aplica a todas as grandes regiões do Brasil (IBGE, 2005). 
Há um aumento expressivo e consistente da alfabetização da população durante todo o século XX. Em 1900 apenas 34,7\% das pessoas com 15 anos ou mais de idade eram alfabetizadas. No final deste século esse indicador é de 80,0\% (IBGE, 2005). Um aumento de pouco mais de $130 \%$.

A questão que se coloca sobre estes índices é qual analfabetismo estamos tratando e como são os alfabetizados. Pesquisas recentes divulgadas por jornais de grande circulação nacional, como Folha de São Paulo, Estado de S. Paulo e Jornal O Globo, mostram como estão os alunos de escolas públicas e particulares. O nível dos alunos caiu em referencia aos anos anteriores, mostrando que as pesquisas que apontam o nível de analfabetismo no país o fazem de maneira parcial e tendenciosa, já que o ser alfabetizado, muitas vezes, é o saber escrever o nome. Se a idéia de alfabetização é dar acesso a informação e oportunidade de emprego, não se pode construir índice de Qualidade de Vida apoiado neste tipo de alfabetização, somente com análises macro-estruturais da educação brasileira, como o Sistema Nacional de Avaliação do Ensino Básico, é possível apontarmos caminhos para a implementação de projetos que atinjam os objetivos de transformação social. Ao estabelecer parâmetros sem intermediação destes problemas de aplicação, ou uma melhor metodologia dos questionários teremos uma falsa representação da realidade educacional brasileira. Porque de um lado temos a diminuição do analfabetismo, e por outro a menor qualificação dos alunos da rede pública.

A taxa de matrícula no $2^{\circ}$ grau tem melhorado de maneira ininterrupta de 1940 até os dias atuais. Em 1940 os matriculados no ensino secundário correspondiam a 6,2\% da população entre 15 e 17 anos. Em 1960 essa taxa era de 18,1\%, e em 1991 em torno de 40\% (IBGE, 2005). Mesmo considerando-se que os dados disponíveis não incluem os cursos técnicos nem pedagógicos, não há dúvida de que o ensino de $2^{\circ}$ grau está longe de abarcar toda a sua clientela potencial.

A crise de qualidade do ensino público básico é fruto de uma massificação da educação básica que resultou na diminuição de sua qualidade. Houve uma mediocrização, no sentido exato do termo, da educação. Reflexo de um processo de desvalorização dos professores falta de investimento nas escolas e valorização do ensino particular (Oliveira, 2004).

A saída de uma política pública consciente é tratar da qualidade no ensino público. A qualidade das escolas públicas, ou pelo menos de muitas delas, deve ser suficiente para que haja, de fato, igualdade de oportunidades no Brasil. O estudante de escola pública deve ser preparado para competir em igualdade de condições com estudantes treinados em boas escolas da rede privada, por um lugar nas melhores universidades do Brasil. Isto é uma política educativa ampla de acesso e inclusão que terá impacto na Qualidade de Vida da população. 


\subsection{Serviços Públicos Básicos}

A qualidade de vida depende também de vários indicadores que expressam serviços públicos básicos. Dentre eles destacamos a oferta de rede geral de água, de rede sanitária, coleta de lixo, de eletrificação residencial e de estabelecimentos de saúde e médicos por mil habitantes. Em todos eles o Brasil apresenta melhorias nos Índices de Desenvolvimento Humano (2001).

Rede geral de água significa água centralmente coletada e tratada, o que contribui para a redução de inúmeras doenças transmissíveis através da água e, conseqüentemente, diminuição da taxa de mortalidade infantil e aumento da esperança de vida ao nascer. A rede geral de esgoto é outro serviço público básico que, juntamente com a rede geral de água, melhora a qualidade da água, contribui para a redução da mortalidade infantil e o aumento da esperança de vida ao nascer. É óbvio que melhor qualidade de vida está associada a um abrangente serviço de rede geral de esgoto. A alternativa a isto é, em geral, nos sítios urbanos, a vala negra e o esgoto a céu aberto. Nesse caso, tanto a população infantil quanto a adulta fica exposta a doenças infecciosas e parasitárias. A sujeira atrai também animais nocivos à saúde, como ratos, e degrada as condições de vida e o meio ambiente.

O lixo coletado é também um serviço básico que tem relação direta com a saúde pública e o meio ambiente. Quanto maior a proporção de domicílios atendidos por esse serviço, menos sujeira é acumulada em áreas residenciais, menor é a possibilidade de formação de focos de doenças e, como conseqüência, melhor é a qualidade de vida (Almeida, 1998).

A eletrificação residencial é igualmente fundamental para a qualidade de vida. Não apenas porque fornece acesso à iluminação elétrica noturna, mas principalmente por permitir à população a utilização de geladeira, fundamental para a conservação dos alimentos em países tropicais, e de inúmeros aparelhos eletrodomésticos fortemente associados à qualidade de vida como, por exemplo, TV, rádio, liquidificador e chuveiro elétrico. A eletrificação residencial é mais um indicador relevante para a qualidade de vida a apresentar melhora constante nos anos para os quais o dado existe. Em 1970, 47,6\% dos domicílios tinham energia elétrica; em 1995, 91,7\% das residências já possuem iluminação elétrica, geladeira e televisão, neste século cerca de 93\% possuem iluminação (IBGE, 2005).

Segundo Almeida (1998): "Note-se que, por causa da preponderância assumida pela televisão, a energia elétrica é um importante fator de conforto e informação. Maior abrangência da eletrificação residencial significa população mais bem informada e tempo livre usufruído de forma mais agradável". 
Avançamos neste artigo afirmando que a melhoria nos índices, olhados de forma estanque, não conjuntural. Podemos olhar para estes dados com outro olhar, diferente do apontando, mostrando que o governo não tem uma atuação pró-ativa nestas ações, vinculados muito mais a uma exigência econômica do que políticas participativas que visem o bem público. Necessidade de ampliar o número de consumidores, levando a cada casa os produtos e pensamentos de setores que detêm os meios de comunicação. Não colocamos a televisão como algoz do desenvolvimento da qualidade de vida no Brasil, entretanto é necessário termos, tal qual a iluminação, 93\% de alfabetizados em escolas públicas com níveis mínimos de exigência e qualidade. Ampliam-se, por um lado, os avanços e aquisição de bens de consumo, que veremos no próximo parágrafo, e, por outro lado, segue urgente a constituição de agendas que se preocupem com a educação, saneamento básico e acesso a bens culturais diversos.

A aquisição de bens e consumo materiais deu-se principalmente no "milagre econômico", momento de constituição de uma classe média, que possibilitou maior investimento nas indústrias destes produtos aumentando sua oferta (Almeida e Gutierrez, 2005). Hoje é possível ter um eletrodoméstico morando num barraco de alguma área de risco social. Outro ponto a salientar é o processo de afastamento dos centros urbanos, a chamada periferia. Um dos problemas dos contingentes de desassistidos socialmente que migram para os centros urbanos é o da proliferação de bairros à margem dos centros de empregos, dificultando o papel das prefeituras em oferecer os serviços básicos de infra-estrutura, já que é freqüente a tomada de espaços para formação de bairros sem planejamento.

Apesar do aumento da coleta de esgoto e do serviço de iluminação pública, em números absolutos, as ações são pouco eficazes, em números relativos, se comprado ao desenvolvimento destas novas moradias clandestinas. Muitas vezes estas pessoas não podem custear sequer o serviço de iluminação pública que é pago na conta de luz. Ao não custearem o serviço o setor público, através das empresas concessionárias, não investe nestas localidades.

No que diz respeito à instalação sanitária, não existem dados entre 1985 e 1990. Em 1960, cerca de $15 \%$ dos domicílios brasileiros contavam com rede geral de esgoto. Em 1995, este número é de aproximadamente 40\% (IBGE, 2005). A coleta evita o esgoto a céu aberto e as conseqüências disto para a saúde pública. No IDH (2001) o Brasil aparece como um dos países da América do Sul com menores índices de acesso a rede geral de esgoto.

Nem sempre o esgoto coletado em rede é devidamente tratado. Apesar de diminuir o risco de doenças nas localidades que são construídos, o não tratamento do esgoto leva a uma piora nos índices macros de qualidade de vida, já que o acesso a água potável é um dos grandes problemas deste começo de século (PNUD, 2001). Ao não tratar a água e aumentar o recolhimento de esgoto 
você maximiza a poluição nos rios, mananciais, mares e demais áreas ribeirinhas e/ou litorâneas democratizando assim a poluição e a degradação ambiental.

Este é mais um exemplo de falta ações integradas nas políticas públicas das secretárias dos diferentes órgãos de poder, se por um lado aumenta-se a rede de captação do esgoto, por outro lado, não é tratado este esgoto, atingindo a água potável, a flora e fauna e logicamente a qualidade de vida das populações onde é despejado este esgoto.

\subsection{Saúde}

A medição da oferta de serviços de saúde pelos dados do IBGE revela avanços. Houve acréscimo absoluto e relativo de estabelecimentos de saúde e de médicos das décadas de 40 e 50 , respectivamente, até os dias atuais. No que diz respeito a estabelecimentos de saúde, em 1940 existia um para cada 26.200 habitantes; em 1992 tínhamos apenas 3 mil habitantes para cada unidade. Quanto aos médicos, em 1950 eram 0,38 para cada mil habitantes; em 1992 este indicador já havia atingido a marca de 2,1 .

Nas capitais, entre 1930 e 1989, houve uma acentuada diminuição da proporção de óbitos por doenças infecciosas. Por outro lado, a proporção de mortes resultantes de doenças circulatórias $3 / 4$ coração e derrame principalmente $3 / 4$ e neoplasias $3 / 4$ que engloba todos os tipos de câncer $3 / 4$ tem crescido de forma constante. As duas causas desse fenômeno são: a melhoria da qualidade de vida e a mudança do perfil etário da população. Melhor qualidade de vida resulta em mais saúde, que aumenta a expectativa de vida. Somando-se à redução da taxa de fecundidade, ocorre um envelhecimento da população. As mortes causadas por câncer ou doenças circulatórias são típicas de pessoas com saúde e longevidade, pois a sua incidência aumenta com a idade. Elas já representam, separadamente, hoje, no Brasil, uma proporção maior de causa mortis do que as doenças infecciosas.

Nota-se a tendência de melhora. As doenças da velhice continuam liderando e as infecciosas e parasitárias mantêm tendência de queda.

Merece registro o aumento permanente das causas externas de mortandade. Reflexo da violência criminal e no trânsito. Trata-se de um problema grave que ainda está por merecer um combate mais sistemático e eficaz. Esta estatística exemplifica algo para o qual este artigo chama a atenção: as melhoras coexistem com pioras e coisas a serem feitas. A violência é fruto de políticas sociais sem direcionamento específico, de formas de exclusão expressos na falta de educação, acesso aos bens materiais mínimos e políticas de inclusão social (Almeida, 2003). A violência no Brasil influi negativamente na causa mortis de jovens do sexo masculino, tendo um grande problema que deve ser acompanhado em conjunto com as políticas sociais de maneira ampla. $\mathrm{O}$ 
aumento da criminalidade reforça a tese de problemas de distribuição de renda, acesso a emprego e esvaziamento do setor público em áreas de risco social, apontando que uma política de inclusão social passa também pelos meios de correção como as Casas Corretivas de Menores Infratores e as

Casas de Detenção e os Presídios, que hoje são depósitos de pessoas e não possuem relação de reeducação e re-inserção social do indivíduo que perdeu provisoriamente a sua liberdade.

Quanto aos acidentes no trânsito, parte de uma política de educação, maior vigilância e controle social, e, principalmente, melhores condições das estradas, das sinalizações e de uma ação efetiva aos trabalhadores que atuam na área de transporte de mercadorias e passageiros.

\subsection{Mortalidade Infantil}

A taxa de mortalidade infantil e a expectativa de vida ao nascer foram deixadas para o final dessa seqüência de dados porque sintetizam um avanço. A queda do primeiro e a conseqüente melhora do segundo indicador só foram possíveis porque há hoje no Brasil mais leitos por mil habitantes, mais saneamento, água tratada, lixo coletado, estabelecimentos hospitalares, mais alfabetizados (o que significa mais gente bem informada) do que no passado. A propensão de melhora de ambos é reflexo da melhora dos outros indicadores.

Além disso, para anos mais recentes, são apresentadas as taxas de mortalidade dos respectivos anos. Entre 1930 e 1940 a média da década foi de pouco mais de 158/1000, sendo de quase 88 para o período 1970-1980. A mesma taxa de mortalidade infantil no ano de 1993 foi de 43,4. Apesar de ainda estarmos distantes das taxas dos países desenvolvidos, a melhoria foi bastante acentuada no período considerado, a qual teve um reflexo significativo na expectativa de vida do brasileiro (IDH, 2001).

Apesar de não haver políticas públicas de grande porte a mudança foi grande e para melhor. E isto se aplica a todas as regiões do Brasil. Em 1940 a esperança de vida ao nascer era algo em torno de 42 anos de idade; hoje ela situa-se próxima aos 67 anos.

\section{Políticas integradas}

Uma análise comparativa com os países para os quais existem dados sobre renda mostra que o Brasil é o país que apresenta um dos maiores índices de desigualdade no mundo, e que a distribuição de renda piorou entre 1960 e 1990 (a mais acentuada piora ocorreu entre 1960 e 1970). De acordo com esse tipo de objeção, o presente artigo pecaria por ignorar esse elemento, talvez o mais importante, da situação socioeconômica na qual o Brasil se encontra. Este fato demonstra claramente que os avanços sociais são direcionados para o consumo e não a uma política de 
participação social. Mantendo a população na exclusão, porém com alguns avanços no acesso a alguns bens duráveis.

O Brasil, segundo o Programa e Desenvolvimento Humano (2001), investe pouco na qualificação humana, cerca de $0,8 \%$ do PIB, nossos pesquisadores tem menor escolarização que Panamá e Trinidad Tobago, a população brasileira ainda tem pouco acesso a inovações antigas como telefone e eletricidade - índices menores que Uruguai e Peru -, além de existir pouca interface entre a produção de inovação e os benefícios sociais vindos dela. Os mesmo problemas constatados no Índice de Desenvolvimento Humano, como distribuição de renda e escolarização, interferem nos índices de inovação tecnológica.

Apesar de o Brasil possuir dois pólos industriais de tecnologia de ponta, não consegue uma interface da inovação com acesso, afetando negativamente na qualidade de vida. Já que a formação dos cientistas (número de anos) é inferior a média dos líderes e líderes potenciais, como também, a população ainda não tem acesso a tecnologias já difundidas, como consumo de eletricidade e telefone (RDH, 2001, p.48 e 49).

Não devemos comparar as discussões teóricas sobre a qualidade de vida com as ações práticas e grupos de controle da política. Pois a discussão a respeito de políticas de qualidade de vida é muito distinta da discussão sobre o objeto de pesquisa da qualidade de vida. A passagem de um referencial para outro é cheio de conseqüências e transformações. Enquanto a pesquisa teórica busca ampliar o conhecimento acumulado a respeito de um determinado assunto, a prática política busca a ampliação do poder dos agentes e o controle político de suas bases. Assim, o investimento na área de qualidade de vida deve entrar em disputa com outras secretárias, tornando inviável, muitas vezes, a opção por uma nas políticas públicas de qualidade de vida.

Por isso a qualidade de vida é uma opção fraca politicamente, estando, dentro do cenário político em segundo plano, tendo em vista os campos como: Controle Inflacionário, Investimento no Etanol e Pagamento da Dívida Externa. Pensar a política de qualidade de vida é praticamente sinônimo de pensar em formas de aumentar o peso da área dentro da constelação mais ampla de alternativas de investimento que se apresentam para os governantes, a partir da inserção num quadro nacional com forte influência das práticas de sustentação no poder, onde governar muitas vezes confunde-se, ou até mesmo resume-se a distribuir verbas e cargos (Gutierrez e Almeida, 2006).

Desta linha de raciocínio, um primeiro aspecto essencial é o caráter dúplice das políticas públicas de qualidade de vida. A qualidade de vida deveria ser vista como melhoria do estilo de vida e condições de vida (Gonçalves, 2004). Associar as políticas públicas a esta ordem é muito complicado já que as ações, segundo Gonçalves (2004), priorizam a mudança subjetiva no estilo de vida, sem dar as condições materiais suficientes para ter condições de vida dignas. Esta visão da 
qualidade de vida pode ser analisada em projetos federais de 2003-2006 como Mexa-se, Segundo Tempo, Esporte Lazer na Cidade e Política Nacional Contra o Diabetes, que propiciam ações particularizadas sem possibilitar proporcionar um pensamento articulado entre os diversos setores sociais.

Deste referencial de qualidade de vida, preocupado com o social surgiu a idéia das ações vinculadas à educação, à cultura, à economia e ao trabalho. A qualidade de vida se potencializa na educação social da população e na busca constante pela cidadania. Em outras palavras, o caráter educativo e pedagógico justifica a inserção da qualidade de vida nas políticas públicas, já que a condição de vida e estilo de vida, incontestavelmente, são fatores primordiais para o avanço global da sociedade.

A implementação de uma política de qualidade de vida dá-se no interior de um projeto político mais amplo e através de uma máquina de administração pública dominada, durante um período de tempo específico, por um partido político ou, ainda, por uma tendência integrante de um partido político. A expectativa do controle de verbas para serem distribuídas, mais a necessidade de lotear as diferentes secretarias entre os grupos que irão compor uma base parlamentar de apoio, leva a execuções de ações administrativas de uma forma não coordenada e independente umas das outras, em função dos interesses específicos de cada grupo instalado na estrutura de poder. Assim, é extremamente difícil articular as propostas do campo da qualidade de vida com as de outras áreas como saúde, habitação, educação, pensando-as globalmente.

\section{Considerações finais}

O grande desafio para a humanidade é transformar a tecnologia num instrumento para o desenvolvimento humano, isto requer, muitas vezes, um esforço deliberado e investimento público para criar e difundir amplamente as inovações. Não basta investir na criação, adaptação e comercialização de produtos necessários, mas sim no acesso a estes avanços, através de políticas macro-estruturais que possibilitam a transformação da sociedade.

A sociedade avança, no entanto reflete muito mais aspectos de consumo e mercado de bens e serviços do que políticas amplas que propiciem melhoria das condições de vida da população. Os índices discutidos muitas vezes são utilizados para demonstrar melhorias, porém devem ser vistos com ressalvas.

Para uma qualidade de vida de maneira não-fragmentada, devemos interpretar de maneira macro, como a mecanização do campo, o analfabetismo, o acesso a bens de consumo duráveis e a saúde. Para entendermos o papel das políticas públicas na qualidade de vida. 
A questão que se coloca sobre estes índices é qual qualidade de vida estamos tratando e como são estas pessoas que os números refletem. A saída de uma política pública consciente é tratar da qualidade de forma articulada com diferentes setores da sociedade. Passando pelas escolas, acesso a rede de esgoto, rede elétrica, conjuntamente com um processo de inclusão social e participação da população nestas políticas.

Concluímos neste artigo que a melhoria nos parâmetros, olhados de forma fragmentada (estanque), não conjuntural, leva a afirmações rápidas, sem o devido olhar de Condição de Vida e Estilo de Vida. Podemos analisar os dados mostrando que o governo não atua com a preocupação social, muito mais vinculado a uma exigência econômica do que políticas participativas que visem o bem público.

Por fim, a política pública de qualidade de vida, como qualquer outro setor, deve ter uma postura crítica e articular-se, compartilhando objetivos e recursos, além de adotar como critérios fundamentais o incentivo à sociabilidade espontânea, o desenvolvimento integral das pessoas, melhoria nas condições de vida e do auto-conhecimento dos participantes. É neste sentido que procuramos aqui apontar a importância da pesquisa a respeito da qualidade de vida para pensar as políticas públicas de qualidade de vida.

\begin{abstract}
This study it intends analyze the indices of quality of life divulged by IBGE (Brazilian Index of Geography Statistics) and IDH (index of Human Development), pointing that only they will have to be analyzed of an including form, not in singular way, not prioritizing some pointers in detriment of others. The bibliographical analyze and analytical study became separately dialoguing with authors of the area and pointing the spaces of public politics in the indices. One concluded that the studies of quality of life must mediate with very well-taken care of the numbers that if present because many times if show fragile when it is thought about politics of quality of life of great social action. Word key: Public quality of life, politics, social action.
\end{abstract}

\title{
Referência Bibliográfica
}

ALMEIDA, Carlos. O Brasil No Final Do Século XX: um caso de sucesso. Revista Dados v. 41, n. 4, Rio de Janeiro, 1998.

ALMEIDA, Marco. Lazer e presídio: A relação que não se busca. In: Licere. Vol. 6, №.3, Belo Horizonte, 2003.

ALMEIDA, Marco e GUTIERREZ, Gustavo. O Lazer no Brasil: do nacional-desenvolvimentismo à globalização. In: Conexões, <http://www.unicamp.br/fef/publicacoes/conexoes> Revista Digital - Campinas-Unicamp, V. 3 № 1, 2005.

GONÇALVES, Aguinaldo. Em busca do diálogo do controle social sobre o estilo de vida. In: VILARTA, Roberto (Org.). Qualidade de vida e políticas públicas. Campinas: IPES, 2004. p.17-26.

GUTIERREZ, Gustavo e ALMEIDA, Marco. Conflito e gestão da qualidade de vida nas organizações. VILARTA, Roberto (Orgs.). Qualidade de vida e fadiga institucional. Campinas: IPES, 2006.p.85-96 
IANNI, Octavio. A era do globalismo. 7a ed. Rio de Janeiro: Civilização Brasileira, 2002.

IBGE, 2005. www.ibge.gov.br. Visitado em 19/04/2007.

MANTEGA, Guido. Marxismo na economia brasileira. In: MORAES, J. (Org.). Historia do marxismo no Brasil II: Os influxos teóricos. Campinas: Editora da Unicamp, 1995.

OLIVEIRA, Marcus Aurélio Taborda de. Educação Física escolar e ditadura militar no Brasil ( 1968-1984): entre a adesão e a resistência. In: Revista Brasileira de Ciências do Esporte, v.25, n.2, Campinas, Autores Associados, pp. 9-20, 2004.

RELATÓRIO DE DESENVOLVIMENTO HUMANO. Novas tecnologias e desenvolvimento humano. Programa das Nações Unidas para o Desenvolvimento. Lisboa, Portugal: Trinova Editora, 2001.

\section{Dados completos dos autores}

\section{Nome completo: Marco Antonio Bettine de Almeida}

Filiação institucional: UNICAMP

Departamento: Programa de Pós-graduação da Faculdade de Educação Física.

Função ou cargo ocupado: Doutorando do programa de Pós-graduação da Faculdade de Educação Física.

e-mail: $\underline{\text { marcobettine@yahoo.com.br }}$

\section{Nome completo: Gustavo Luis Gutierrez}

Filiação institucional: Unicamp

Departamento: Faculdade de Educação Física da Unicamp

Função ou cargo ocupado: Professor titular

Endereço completo para correspondência: Caixa Postal 6134, Cidade Universitária Zeferino

CEP 13083-970 - Campinas, SP - Brasil

Telefones para contato: (19) 3788-6623

e-mail: gutierrez@fef.unicamp.br 